\title{
El Catálogo General del Patrimonio Histórico Andaluz en la Bahía de Cádiz
}

La demarcación de la Bahía de Cádiz está conformada por seis municipios, de los cuales, territorialmente, tres se encuentran afectados parcialmente. En esta zona nos encontramos 122 bienes patrimoniales inscritos en el Catálogo General del Patrimonio Histórico Andaluz (CGPHA), sin incluir los bienes que han sido protegidos con el expediente del legado patrimonial de los lugares de la Constitución de 1812, que más adelante analizaremos. Al clasificar los bienes por la figura legal que les da protección, nos encontramos que hay 99 bienes de interés cultural (BIC) y 23 de catalogación general. Además, fuera del Catálogo General tenemos un bien que afecta a los seis municipios: se trata del espacio subacuático de la Bahía de Cádiz declarado zona de servidumbre arqueológica y 16 bienes incluidos en el Inventario de Bienes Reconocidos del Patrimonio Histórico Andaluz.

Bienes de interés cultural

\begin{tabular}{ll}
\hline Tipología & Bienes \\
\hline Monumento & 69 \\
\hline${ }^{*}$ Arquitectura militar & 32 \\
\hline Zona arqueológica & 18 \\
\hline Conjunto histórico & 6 \\
\hline Sitio histórico & 2 \\
\hline Lugar de interés etnológico & 2 \\
\hline Otros & 2 \\
\hline Total & 99 \\
\hline
\end{tabular}

La Ley 14/2007 de 26 de noviembre de Patrimonio Histórico de Andalucía crea en el artículo 13 un nuevo instrumento muy relacionado con el planeamiento urbanístico, denominado Inventario de Bienes Reconocidos del Patrimonio Histórico Andaluz, donde se pueden recoger e identificar bienes integrantes del patrimonio histórico fuera del Catálogo General, dándoles, a su vez, una protección urbanistica.

La Dirección General de Bienes Culturales hace uso de este instrumento y por Resolución de 7 de septiembre de 2009, incluye en el Inventario de Bienes Reconocidos del Patrimonio Histórico Andaluz los bienes inmuebles de la arquitectura contemporánea, sitos en la provincia de Cádiz, con lo cual se crea el primer expediente administrativo donde se identifican y protegen 28 bienes, 16 de ellos se encuentran en municipios de la Bahía de Cádiz.

De igual modo, desde la Dirección General de Bienes Culturales, se ha ido fomentando los expedientes que dan protección a bienes relacionados con la arquitectura moderna. Así en 2001 se inscribió en el Catálogo General del Patrimonio Histórico de Andalucía (CGPHA), con el régimen de Catalogación General, "Dieciséis Bienes de la Arquitectura del Movimiento Moderno (DOCOMOMO) situados en distintas provincias de Andalucia", dos de los cuales se encuentran en Cádiz y en San Fernando; y el expediente inscrito en 2007 también con el régimen de Catalogación General denominado Cuatro Bienes Inmuebles del Movimiento Moderno de la provincia de Cádiz, encontrándose dos de ellos en Puerto Real y dos en el municipio de Cádiz.

También en el año 2004 con el régimen de catalogación general se finaliza el procedimiento para la inscripción en el CGPHA, del expediente denominado Jardines de interés cultural ubicados en Cádiz y su provincia, donde se protegen 27 jardines de los cuales 18 se encuentran en municipios de la Bahía de Cádiz.

Pero lo más singular en relación con los bienes protegidos en la zona a tratar es lo referente a la arquitectura militar, sobre todo a la línea de defensa costera de la Edad Moderna donde nos encontramos baterías, fuertes, baluartes y demás elementos defensivos, a los cuales se le ha otorgado la protección de bien de interés cultural, la mayoria en virtud de la disposición adicional segunda de la Ley 16/1985, la cual se refiere al Decreto de 22 de abril de 1949 de protección de los castillo españoles. Con la nueva Ley 14/2007, de 26 de noviembre, de patrimonio histórico andaluz, quedan inscritos en el Catálogo General del Patrimonio Histórico acogiéndose a la disposición adicional tercera.

Para concluir, habria que hablar de uno de los últimos expedientes que se ha finalizado en la Dirección General de Bienes Culturales, el cual destaca no sólo por lo que significa históricamente sino por la gran cantidad de bienes que se protegen en un único acto administrativo. Se trata del Legado patrimonial de los lugares de la Constitución de 1812 en la Bahía de Cádiz, donde 3.099 bienes, de diferente naturaleza patrimonial, han sido inscritos en el Catálogo General del Patrimonio Histórico como bienes de interés cultural, bajo la tipologia de sitio histórico.

\begin{tabular}{ll}
\hline Patrimonio inmueble & 92 \\
\hline Patrimonio mueble & 246 \\
\hline Patrimonio documental & 1.629 \\
\hline Patrimonio bibliográfico & 1.132 \\
\hline
\end{tabular}

El Catálogo General del Patrimonio Histórico Andaluz está abierto a la consulta pública en la página web de la Consejería de Cultura, dentro del área de Bienes Culturales: www.juntadeandalucia.es/cultura

Olga Viñuales Meléndez Juan Antonio Pedrajas Pineda Consejeria de Cultura

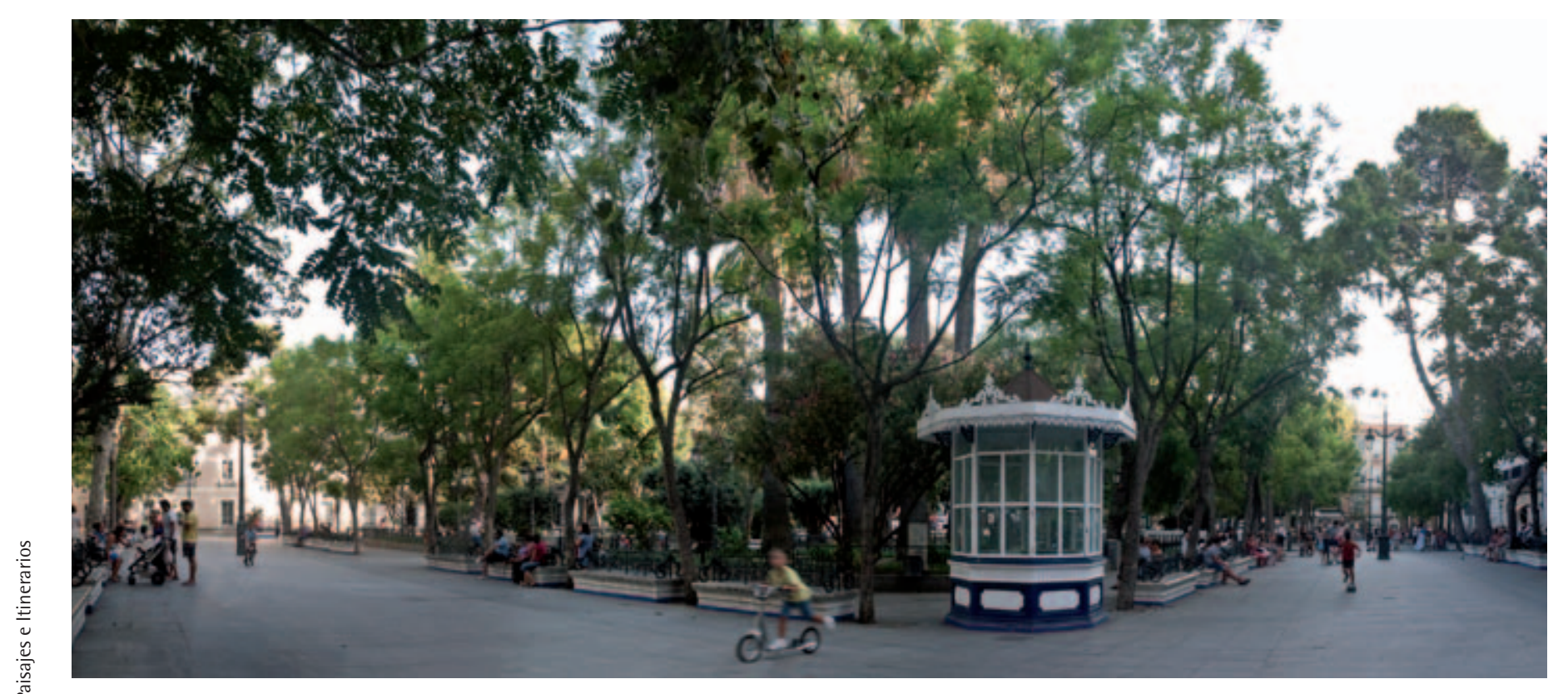

Plaza de Mina, jardín de interés cultural ubicado en Cádiz. Foło: Fondo Gráfico IAPH (Isabel Dugo Cobacho) 


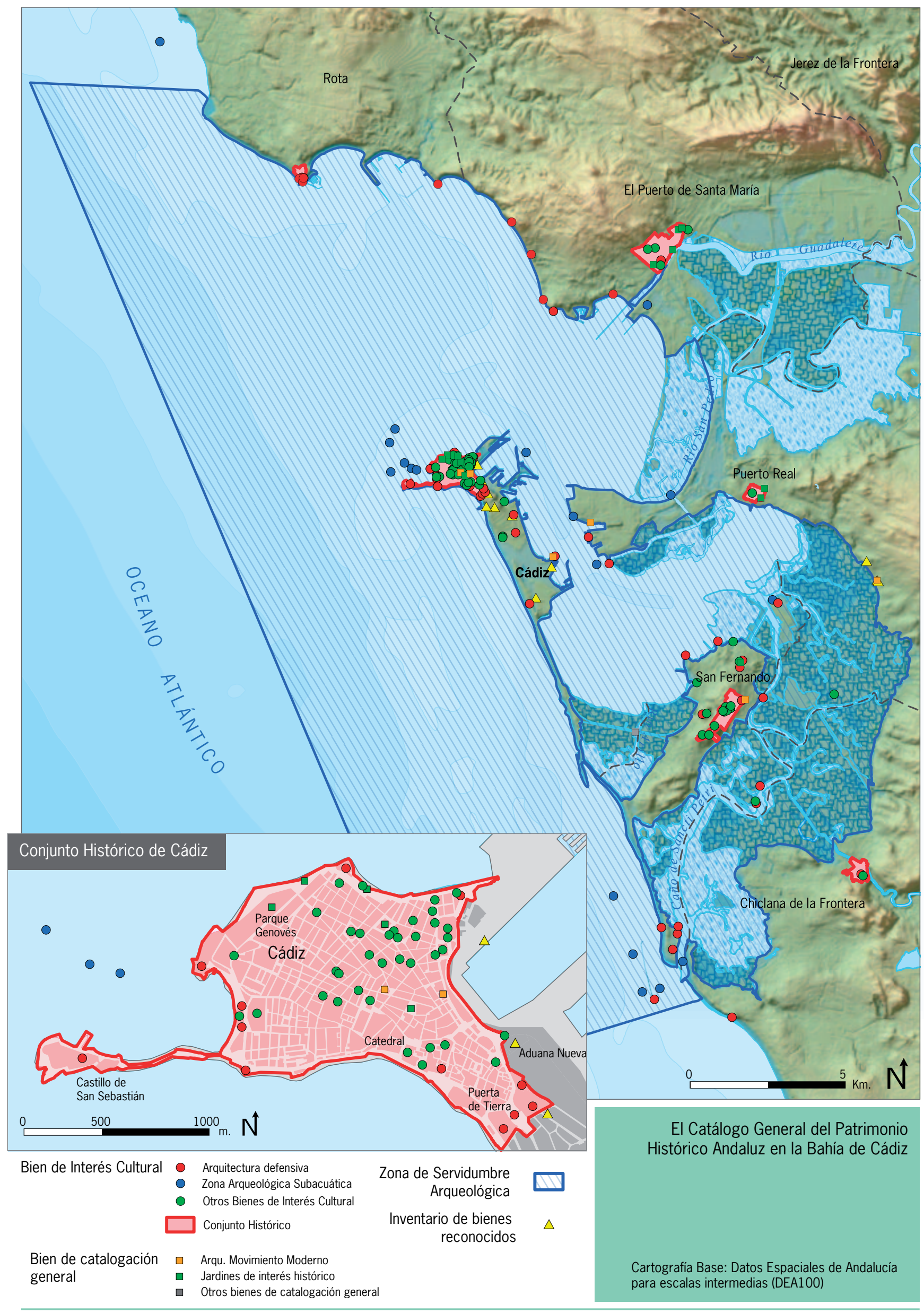

